\title{
Impact of the degree of grinding of siliceous opoka-like rocks on properties of ceramic products
}

\author{
Julia Terekhina ${ }^{1}$, Julia Bozhko $^{2}$, Kira Lapunova ${ }^{3}$ and Lyudmila Postoi ${ }^{4}$ \\ ${ }^{1}$ Engineer, Don state technical University, 344022 Gagarina,1, Rostov on Don, Russia \\ ${ }^{2} \mathrm{PhD}$ student, Don state technical University, 344022 Gagarina, 1, Rostov on Don, Russia \\ ${ }^{3}$ Assistant professor, Don state technical University, 344022 Gagarina,1, Rostov on Don, Russia \\ ${ }^{4}$ Assistant professor, National Research Nuclear University MEPhI, 347360, Lenina, 73/94, \\ Volgodonsk, Russia
}

\begin{abstract}
This work presents the results of the laboratory research on the impact of grain size composition of raw mixtures on properties of heat processed products when implementing the compression molding method. We have analyzed opokas of several fields: Zhuravksy, Shevchenkovsky and Bekeshevsky. Grain size composition of ground materials was characterized by a greater grain size of 0,$315 ; 0,63 ; 1,25$ and $2,5 \mathrm{~mm}$. The link between degree of grinding and caking index, water absorption, mean density, compression and bending resistance was established. The conclusions based on the research results revealed the impact of grain size composition on properties of ceramic products and application potential of opokas as a feedstock in the ceramics industry.
\end{abstract}

\section{Introduction}

Wall ceramics have always been one of the main types of construction materials in building engineering. In recent years, the Russian industry of wall ceramics has been gradually improving its performance both quantitatively and qualitatively. New factories are being built, the product range is being expanded, but this happens overwhelmingly due to the supply of imported technological lines of plastic molding, while construction of semi-dry molding plants is rare cases. However, according to the domestic and foreign experience, as well as the technical and economic analysis, compression molding technology has a number of advantages and becomes widespread in Russia and in Western Europe [1-4].

It should be emphasized that the term "semi-dry molding" is not really correct scientifically and technically, and it has developed historically. The term "compression molding" is more appropriate, which is proposed G.D. Ashmarin and other researchers [5]. In our work, we will use the term "compression molding", which, taking into account a number of factors, more accurately reflects the process of manufacturing products from a press powder of different humidity in closed forms at a pressure above $10 \mathrm{MPa}$. In this 
work, we will consider the processes, like natural opoka-like rocks in General, and their lithological subgroups with significant differences in composition and properties (fig.1): carbonate, clayey, carbonate-clayey and clayey-carbonate.

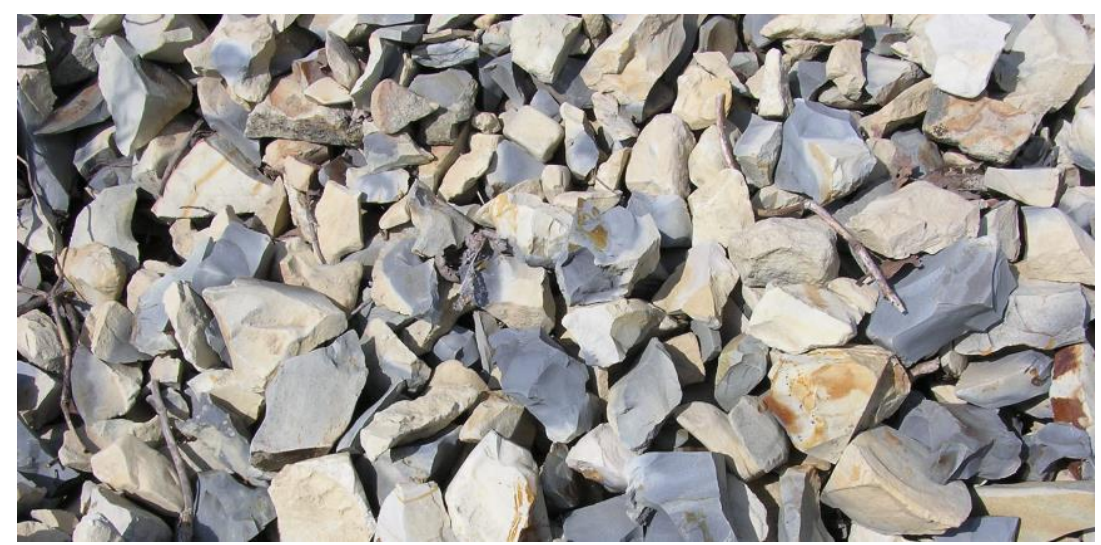

Fig.1. Opoka-like rocks of the South of Russia

\section{Methods}

To assess the impact of the degree of grinding of siliceous opoka-like rocks on properties of ceramic products we in the laboratory tests conducted by us the grain composition of reduced raw materials was characterized by the largest grain size of $0.315 ; 0.63 ; 1.25$ and $2.5 \mathrm{~mm}$. The fractional composition of each of these types of powders is presented in Table 1. It should be noted that when grinding softer varieties of opokas, more fine fractions are formed. Moisture content of original material has a high impact on the fractional composition of the reduced raw material, in addition to the equipment used and its adjustment. For example, moisture content of opokas during grinding by hammer swing mills is maintained in the range of 10-20\% (lower for clayey varieties and higher for thin clay high-porosity opokas). At this moisture content raw materials is well ground and dusting is minimized, which is very important in production conditions. This fact was repeatedly confirmed during pilot-scale tests on various items of equipment. So overdrying of raw materials is unacceptable. Good grinding capacity of opokas with high humidity is due to their high microporosity and correspondingly high moisture capacity.

Table 1. Grain composition of reduced samples of clayey varieties

\begin{tabular}{|c|c|c|c|c|c|}
\hline \multirow{2}{*}{$\begin{array}{c}\text { Greater grain size } \\
\text { of reduced raw } \\
\text { material, mm }\end{array}$} & \multicolumn{5}{|c|}{ Fraction content, mm, \% by weight } \\
\cline { 2 - 6 } & $2,5-1,25$ & $1,25-0,63$ & $0,63-0,315$ & $0,315-0,16$ & $<0,16$ \\
\hline 2,5 & $12-16$ & $14-22$ & $14-22$ & $16-22$ & $26-36$ \\
\hline 1,25 & - & $12-18$ & $20-28$ & $22-28$ & $30-42$ \\
\hline 0,63 & - & - & $18-28$ & $26-36$ & $38-54$ \\
\hline 0,315 & - & - & - & $34-50$ & $48-68$ \\
\hline
\end{tabular}


In production conditions, the achievement of the required degree of grinding is possible on miscellaneous equipment including but not limited to hammer and rotary crushers, disintegrators, shaft and rod mills. Its specific choice when designing is due to the individual characteristics of raw materials and technical and economic factors of production.

\section{Results}

As a result of the complex of laboratory tests with the use of certified equipment installed it was established that the grain size of reduced opokas and opoka-like rocks has a significant effect on their pre-firing ceramic properties [6]. Based on the analysis of literature and previous experimental studies, it can be said that the degree of grinding will also have a significant effect on high-temperature properties of opokas and no-swelling varieties of opoka-like rocks. The process of linear change downwards during drying and firing is called firing shrinkage. It is a quantitative characteristic of the sintering process and one of the demonstrations visible to the naked eye. When firing shrinkage takes place, mechanical stresses opposite to the stresses caused by thermal expansion appear. If ceramic raw materials can be referred to the category of caking, then it has a linear firing shrinkage of about $10-15 \%$, which is $15-20$ times greater than the total thermal expansion. Firing shrinkage allows observation of the products during firing, preventing the appearance of defects (chipping, cracks, variation in plane). Besides, on the basis of the firing shrinkage data, it is possible to select firing temperatures, types of boxing-in and adjust a processing line. When determining the value of firing shrinkage, it is necessary to focus on the possible temperature difference in the product body during firing. It is important to know this in order to determine the dimensions of the formed raw material and the finished product after drying and firing [7]. Speed and caking index greatly increase when the grain size decreases. Therefore, a finer grinding of the material is preferred for sintering intensification. It can be explained by a number of factors: an increase in the initial total surface of the grain body, which is equivalent to the increase in free surface energy, the driving force of the sintering process, a reduction in the diffusion path of vacancies and atoms (reduced distances between vacancies sources and sinker), an increase in the number of contacts of grains per unit volume, i.e. a number of jumpers, the movement of which leads to the filling of pores with material [8]. To achieve the same sintering degree, it is possible to significantly reduce the firing temperature. However, in production conditions the matter of reducing the firing temperature or increasing the dispersion of raw materials is resolved individually in each specific case on the basis of production features.

According to many researchers working in the sphere of ceramics and refractory materials, a monosize powder or a similar powder usually sintered less intensively than a polysize powder that contains grains of various sizes, which is explained by the larger surface of mutual contact of grains in polysize powders [8-10].

Analyzing pre-firing ceramic properties of opokas it can be said that their clayey varieties are more suitable for the plastic molding process, to a lesser degree - moderately clayey opokas (both carbonate and non-carbonate varieties) and mixed clayey-carbonate opoka-like rocks. Accordingly, these varieties were used for experiments on the impact of the degree of grinding of raw materials on sintering and strength properties. In our opinion, preliminary experiments made it possible to determine the appropriate firing temperature for a particular type of raw material. At the same time, as already mentioned, it is better to evaluate the fractional composition of reduced raw material by the sieve method. Due to the high microporosity of opokas, the evaluation of the specific surface is not accurate. Besides, sieve analysis is most convenient in production conditions. 
The results of the conducted experiments confirmed the reasonable assumptions about the impact of the grain composition of powdery opokas and opoka-like rocks on sintering. Table 2 contains information on firing shrinkage, water absorption and mean density depending on the degree of grinding for the clayey opoka of the Shevchenkovsky field, the carbonate moderately clay opoka of the Zhuravsky field and the clayey high-carbonate opoka-like rock of the large Bekeshevsky occurrence. Based on the features of the material composition and the results of studying the high-temperature ceramics properties, the firing temperature of $950^{\circ} \mathrm{C}$ was determined for the clayey opoka of the Shevchenkovsky field and the opoka-like rock of the Bekeshevsky occurrence, and $1000^{\circ} \mathrm{C}$ for the moderately clay opoka of the Zhuravsky field. As can be seen from the results of the experiments, when the largest grain size of the ground raw material is reduced from 2.5 to $0.315 \mathrm{~mm}$, the firing shrinkage increases by $0.3-0.5 \%$, which is a slight increase. Even if we take the values of the firing shrinkage at the largest grain size of $2.5 \mathrm{~mm}$ for $100 \%$, an average increase will be $5-16 \%$. The highest indices are typical for the Zhuravsky field. This is primarily due to the peculiarities of its material composition. Small firing shrinkage values indicate that under the values of the grain size composition of reduced opokas and opokalike rocks there is no destruction of the primary natural microstructure or redistribution of the constituent components, particles of opal, calcite and clay minerals. During firing both large and smaller particles of mass have practically the same firing shrinkage. Insignificant increases are due primarily to the denser "packing" of small grains and, to a lesser extent, to an increase in the number of fine-grained fractions.

Table 2. The results of the sintering determination depending on the degree of grinding

\begin{tabular}{|c|c|c|c|c|}
\hline $\begin{array}{l}\text { Name of the field and litho- } \\
\text { technological type }\end{array}$ & $\begin{array}{l}\text { Greater grain } \\
\text { size, } \mathrm{mm}\end{array}$ & $\begin{array}{c}\text { Firing } \\
\text { shrinkage, } \\
\%\end{array}$ & $\begin{array}{c}\text { Water } \\
\text { absorption, } \\
\%\end{array}$ & $\begin{array}{l}\text { Mean } \\
\text { density, } \\
\mathrm{kg} / \mathrm{m}^{3}\end{array}$ \\
\hline \multirow{4}{*}{$\begin{array}{l}\text { Shevchenkovsky - clayey } \\
\text { Firing temperature } 950{ }^{\circ} \mathrm{C}\end{array}$} & 2,5 & 2,2 & 20,4 & 1520 \\
\hline & 1,25 & 2,3 & 19,9 & 1550 \\
\hline & 0,63 & 2,4 & 18,8 & 1590 \\
\hline & 0,315 & 2,5 & 18,1 & 1620 \\
\hline \multirow{4}{*}{$\begin{array}{l}\text { Zhuravsky - carbonate moderately } \\
\text { clay. } \\
\text { Firing temperature } 1000{ }^{\circ} \mathrm{C}\end{array}$} & 2,5 & 3,1 & 22,3 & 1310 \\
\hline & 1,25 & 3,3 & 21,7 & 1340 \\
\hline & 0,63 & 3,5 & 20,0 & 1360 \\
\hline & 0,315 & 3,6 & 19,7 & 1380 \\
\hline \multirow{4}{*}{$\begin{array}{l}\text { Bekeshevsky occurrence - clayey } \\
\text { high-carbonate opakomorphic } \\
\text { rocks. } \\
\text { Firing temperature } 950{ }^{\circ} \mathrm{C}\end{array}$} & 2,5 & 5,8 & 14,8 & 1440 \\
\hline & 1,25 & 5,9 & 14,3 & 1460 \\
\hline & 0,63 & 6,0 & 14,0 & 1470 \\
\hline & 0,315 & 6,1 & 13,9 & 1480 \\
\hline
\end{tabular}

The degree of grinding does not have a significant effect on water absorption. Thus, with a decrease in the largest grain size of reduced raw materials from 2.5 to $0.315 \mathrm{~mm}$, water absorption is reduced by an average of 1.6-2.6\%. If water absorption values are assumed at the largest grain size of $2.5 \mathrm{~mm}$ for $100 \%$, the reduction is on the average $6-$ $12 \%$. This indicates that the water absorption of the ceramic piece is primarily determined by the porosity of the individual grains of the mass, that is, by the natural primary porosity 
of the rock, and, secondarily, by the intergranular porosity. And it is an insignificant decrease in water absorption that can be explained by a decrease in intergranular opened porosity.

When increasing the degree of grinding of opokas and opoka-like rocks, the average density of the burnt samples also increases insignificantly. The maximum increase in the average density is $100 \mathrm{~kg} / \mathrm{m}^{3}$ (opoka of the Shevchenkovsky field), the minimum is $40 \mathrm{~kg}$ $/ \mathrm{m}^{3}$ (mixed clayey-carbonate opoka-like rock of the Bekeshevsky field). In percentage terms, the density increase is $2.7-6.6 \%$.

The results of the effect of the degree of grinding of clayey opokas and opoka-like rocks on the strength properties of burnt samples are presented in Table 3. For example, data are given for the clayey opoka of the Shevchenkovsky field, the carbonate moderate clayey opoka of the Zhuravsky field and the clayey high-carbonate opoka-like rock of the Bekeshevsky occurrence. As can be seen, the degree of grinding has a significant effect on the compression and bending resistance. Thus, when reducing the largest grain size of the ground raw material from 2.5 to $0.315 \mathrm{~mm}$, the compression resistance for the Shevchenkovsky field is increased almost 1.7 times (from 26.8 to $45.2 \mathrm{MPa}$ ), for the Zhuravsky field - 2,1 times (from 18.5 to $43.8 \mathrm{MPa}$ ), and for clayey-carbonate opoka-like rocks -1.3 times (from 25.3 to $33.0 \mathrm{MPa}$ ). Approximately the same increase is observed for the bending resistance. For the Shevchenkovsky field the increase is also 1.7 times (from 9.4 to $16.3 \mathrm{MPa}$ ), for the Zhuravsky field - 2.4 times (from 7.9 to $19.1 \mathrm{MPa}$ ), and for clayey-carbonate opoka-like rocks - almost 1,4 times (from 10,9 to 14,8 MPa).

Table 3. The results of the strength properties determination depending on the degree of grinding

\begin{tabular}{|c|c|c|c|}
\hline $\begin{array}{l}\text { Name of the field and litho- } \\
\text { technological type }\end{array}$ & $\begin{array}{l}\text { Greater grain } \\
\text { size, } \mathrm{mm}\end{array}$ & $\begin{array}{l}\text { Compression } \\
\text { resistance limit, } \\
\mathrm{MPa}\end{array}$ & $\begin{array}{l}\text { Bending } \\
\text { resistance limit, } \\
\mathrm{MPa}\end{array}$ \\
\hline \multirow{4}{*}{$\begin{array}{l}\text { Shevchenkovsky - clayey } \\
\text { Firing temperature } 950{ }^{\circ} \mathrm{C}\end{array}$} & 2,5 & 26,8 & 9,4 \\
\hline & 1,25 & 31,2 & 11,2 \\
\hline & 0,63 & 36,1 & 14,9 \\
\hline & 0,315 & 45,2 & 16,3 \\
\hline \multirow{4}{*}{$\begin{array}{l}\text { Zhuravsky - carbonate moderately } \\
\text { clay. } \\
\text { Firing temperature } 1000{ }^{\circ} \mathrm{C}\end{array}$} & 2,5 & 18,5 & 7,9 \\
\hline & 1,25 & 24,4 & 11,1 \\
\hline & 0,63 & 38,7 & 14,3 \\
\hline & 0,315 & 43,8 & 17,1 \\
\hline \multirow{4}{*}{$\begin{array}{l}\text { Bekeshevsky occurrence - clayey } \\
\text { high-carbonate opoka-like rocks. } \\
\text { Firing temperature } 950{ }^{\circ} \mathrm{C}\end{array}$} & 2,5 & 25,3 & 10,9 \\
\hline & 1,25 & 27,8 & 12,3 \\
\hline & 0,63 & 31,4 & 13,7 \\
\hline & 0,315 & 33,0 & 14,8 \\
\hline
\end{tabular}

A significant increase in strength properties when increasing the degree of grinding based on an analysis of the above experimental results can be explained, first of all, by an increase in the number of contacts between grains per unit volume of material. The strength of individual grains is of secondary importance, although, of course, it affects the strength of the samples as a whole. 
Other reasons for a significant increase in strength correspond to the basic laws of physical chemistry for sintering processes. The strength increase in 1,3-2,1 times with finer grinding of raw materials is important for the technology of wall ceramics. It allows increasing the product brand and void index, which in turn reduces the consumption of raw materials per unit of product, reduces the consumption of fuel and energy resources and generally increases the production profitability. Accordingly, it can be said that opokas are sufficiently technological raw materials. By regulating the degree of grinding, it is possible to vary the strength of products within a wide range. Certainly, this should be correlated with economic efficiency in each specific case.

For opoka of the Zhuravsky field a higher growth of the bending resistance limit is observed. Apparently, this is the result of the presence of calcite, which during firing determines the formation of needle-like and lamellar microlites of wollastonite $(\mathrm{CaO} \cdot$ $\left.\mathrm{SiO}_{2}\right)$ and aluminosilicates of the anorthite type $\left(\mathrm{CaO} \cdot \mathrm{Al}_{2} \mathrm{O}_{3} \cdot \mathrm{SiO}_{2}\right)$. Analyzing the obtained data on the changes in caking capacity and strength properties depending on the degree of grinding can be noted that when the average density increases by $1 \%$, the compression resistance is increased by $10-25 \%$. . Figures 2 and 3 show graphs of the quadratic function of the dependence of the compression resistance on the mean density for the Shevchenkovsky and Zhuravsky fields. Undoubtedly, the obtained data are to some extent relative. In each case, it is necessary to take into account the features of the material composition and sintering of a particular opoka-like raw material.

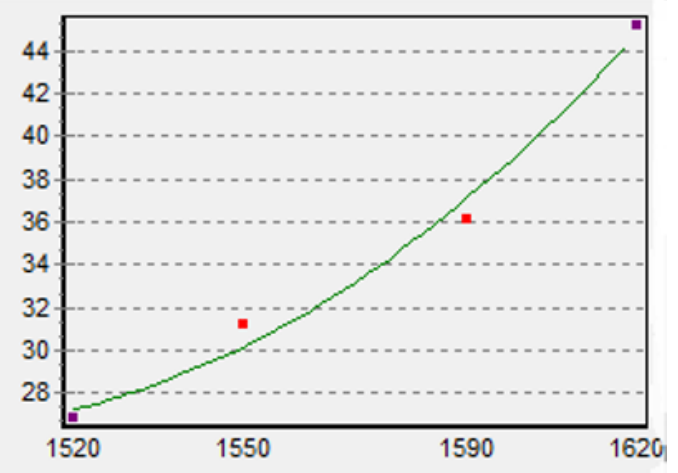

Fig. 2. Functional dependences of the compression resistance limit and the mean density of the sample for opoka of the Shevchenkovsky field

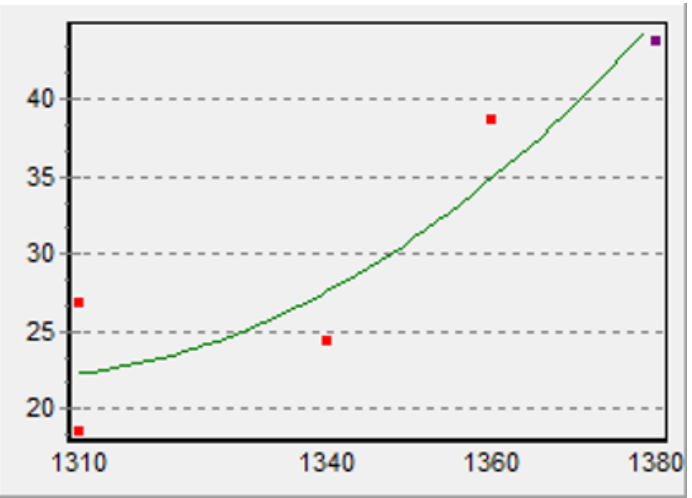

Fig. 3. Functional dependences of the compression resistance limit and the mean density of the sample for opoka of the Zhuravsky field 


\section{Conclusion}

Analyzing the data obtained, it can be said that the degree of grinding of opokas and opokalike rocks within the studied limits does not have a significant effect on sintering. The primary natural fine-grained conglomerate is destroyed to a small extent during grinding. We conducted experiments with a fine grinding of clayey opokas in ball mills to particle size of less than $0.63 \mathrm{~mm}$. With such a grain composition of the reduced raw material, a significant intensification of sintering was observed. However, in the production environment, such a fine grinding of raw materials is not economically sensible and cannot be considered as a technological conversion.

The minimum indices of the change in caking capacity are observed in clay-carbonate opoka-like rocks. It is understandable, as it is a softer rock and soaks with little mechanical impact. Its natural fine-grained structure, like that of clays, is well destroyed during plastic processing of the mass. It is quite difficult to destroy natural structure of more solid stonelike opokas with plastic processing completely.

With increasing temperature, depending on the material composition of the raw material, and an increase in the mean density by $1 \%$, the strength increases by $14-27 \%$. However, the data obtained show general trends of the impact of the degree of grinding on the strength characteristics, the relationship between strength and density. These features of the opoka-like raw materials must be taken into account when testing them, carrying out pre-commissioning activities and optimization of technological production parameters. The laboratory data of the research are of practical importance for the production technology of wall ceramics based on opoka-like rocks of various material compositions. Due to the widespread prevalence of opoka-like rocks in the south of Russia, their use for the production of ceramic bricks with the use of resource-saving technologies will be costeffective and technologically sound both in new plants and existing ones.

\section{References}

1. G.D. Ashmarin, V.V. Kurnosov, S.E. Belyaev, V.G. Lastochkin, Stroitel'nye materialy 2, 8 (2011)

2. V.D. Kotlyar, YU.V. Terekhina, YU.I. Nebezhko, Stroitel'nye materialy 2, 6 (2011)

3. Yu.A. Bozhko, K.A. Lapunova, Vestnik Kyrgyzsko-Slavyanskogo universiteta 4, 86 (2018)

4. V.D. Kotlyar, A.V. Kozlov, A.V. Kotlyar, Yu.V. Terekhina, Vestnik MGSU 10, 95 (2014)

5. V.D. Kotlyar, K.S. Yavruyan, Stroitel'nye materialy 4, 38 (2017)

6. V.D. Kotlyar, Inzhenernyj vestnik Dona 3, 55 (2012)

7. K.A. Lapunova. Yu.A. Bozhko, Vestnik Tomskogo gosudarstvennogo arhitekturnostroitel'nogo universiteta 1, 66 (2018).

8. B. K. Kara-Sal, V.I. Kotelnikov, T.V. Sapelkina, Natural and technical Sciences 2, 160 (2015)

9. V.D. Kotlyar, Yu.V. Terekhina. A.V. Kotlyar, Stroitel'nye materialy 2, 25 (2014)

10. A.Yu. Stolboushkin, G.I. Storozhenko, Stroitel'nye materialy 4, 43 (2011) 